\title{
THE USE OF S\&T INDICATORS IN SCIENCE POLICY: DUTCH EXPERIENCES AND THEORETICAL PERSPECTIVES FROM POLICY ANALYSIS
}

\author{
B. J. R. VAN DER MEULEN \\ Centre for Studies on Science, Technology and Society, University of Twente, \\ P. O. Box 217, 7500 AE Enschede (The Netherlands) \\ E-mail: b.j.r.vanderMeulen@wmw.utwente.nl
}

(Received October 3, 1996)

\begin{abstract}
The relation between bibliometrics and science policy remains underdeveloped. Relevance of new methods to produce indicators is easily claimed, but often without real insight in the policy processes. Drawing on experiences with the use of $\mathbf{S} \& T$ indicators in science policy in the Netherlands and on principal-agent theory, I develop an analytical perspective which enables to assess the role of S\&T indicators in science policy. It is argued that the use of S\&T indicators can only be understood well if one takes the socio- political context with its specific dynamics and rationalities into account.
\end{abstract}

\section{Introduction}

Many bibliometric studies make reference to possible use of the method or the results in science policy. Often studies are explicitly policy-driven. Nevertheless, few studies on S\&T indicators pay attention to the dynamics of science policy, the specific information need of policy makers, and whether S\&T indicators can provide this information. Nor do they assess effects of S\&T indicators on the interactions between the actors in science policy. The references to science policy regularly take for granted that governments or other funders of research can improve their research strategy just by translating the results of S\&T indicator studies in policy measures. The dependency of formulation, implementation, and of the success of such strategies on other actors in the research system is neglected.

The use of S\&T indicators within science policy should not be looked upon as something what is done by individual policy makers or evaluators, but instead as something done within specific socio-political configurations. Science policy is a 
control system. Using a mix of allocation, stimulation, and accounting systems, science policy makers try to control own research programmes and the resources of others to enable these programmes - whether they are at the government level, within research councils, at universities, or are entrepreneurial scientists (Zeldenrust, ${ }^{1}$ Van der Meulen and Rip ${ }^{2}$. Governments and research councils initiate priority programmes and draw in the research competencies of scientists and their laboratories to enable the programmes. Scientists develop research lines and bid for grants and contracts to raise sufficient money to keep their own research going. Actual science policy is the outcome of complex interactions between different actors with partially conflicting, partially congruent as well as complementary interests (Mayntz and Scharpf). ${ }^{3}$

The complexity of the interactions makes it difficult to analyze the effect of S\&T indicators on the policy process. They seem to be only a few more trees in the forest of information used by each of the actors in the policy network. But, we can look at the specific purposes of S\&T indicators as policy information and to the kind of relationships they affect. In most countries, the primary functions of S\&T indicators are monitoring and evaluation as aspects of the relation between the government or an intermediate body and research organisations or parts of them. We can conceptualize this relation as a principal-agent relation and use principal-agent theory to understand the virtues and effects of S\&T indicators in science policy. The relation captures the information asymmetry that seems to be a primary reason for governments (as principals) to encourage the production of $S \& T$ indicators.

\section{The policy context of S\&T indicators}

Principal-agent relations, basically, are relations between actors in which one actor, the principal, transfers resources to one or more other actors, the agents, who should use these resources to realize objectives of the principal that the principal herself cannot realize. One can think of numerous of this kind of contract-like relations. Of these, principal-agent relations are typified by four important characteristics:

- Agents have their own (professional) objectives and interests, which might conflict or only partially overlap with those of the principal. The resources of the principal can be used to satisfy the agent's objectives and interests. Often this possibility is a main reason for an agent to enter into the principal-agent relation. Thus, the principal and the agent have a conflict of interest, which can be solved (from the perspective of the principal) by structuring the relation, for example, by rewards for performances, control, and monitoring. 
- An impediment to the structuring of the relation is the information asymmetry between the principal and the agent. Without additional action, the principal lacks the competence or the information to judge what is sensible to do in order to realize the objectives. Moreover, she often depends on the agents for such judgements. Science policy is an obvious example of this, as scientists are often the leading advisors of governments on science policy issues.

- The principal has the right to monitor, but has little possibilities to do so. One reason is the lack of appropriate information on the activities of the agents. Monitoring systems imply additional costs, and self-reporting by the agents is unreliable without further incentives. Thus, the principal has to find an efficient monitoring or incentive system which is sufficiently effective and has acceptable costs. Within science policy an attractive option is to make use of the interests scientists have to evaluate other scientists, because they are consumers of each other's products.

- The impossibility of complete monitoring implies that the principal has to trust the agent. Especially in long standing principal-agent relations trust is necessary for stability and continuity. Within long standing relations with incomplete monitoring reciprocal trust of the agent in the principal is important as well. Agents are likely to continue good performance if they can rely on rewards for good performance, like continuation or increase of funding or a certain degree of autonomy.

Funding relations in science have always been characterized by a secure balance between autonomy and trust on the one side, and accountability and performance on the other. What has changed, however, is the relative importance of the characteristics and the institutionalization of funding relations. If we can use, with hindsight, the idea of science policy for the early periods of science, science policy systems have grown from 'a set of dyadic relations between patrons and clients, each of them unique' (Westfall ${ }^{4}$ ) via trust-based systems in which funding relations are mediated by research councils and other funding agencies operating mainly by peer review (Turner ${ }^{5}$ ) to present-day science policy in which control and monitoring practices proliferate (Cozzens et al. ${ }^{6}$ ).

Since governments have exercised more interest in the products of science as a direct input in the advancement of society, economy, and industry, their position as a principal has developed. At the same time, science policies have emerged in which independency of control has become vital for maintaining the relationship between the principal and the agent. As a result there is now a role for professional evaluators, science policy studies and for producers of S\&T indicators.

Principal-agent relations are analyzed within neo-institutional economic analyses of organisations or in policy studies of the relation between governments and agencies or other organisations performing functions for the government. The four characteristics 
are translated into the question which monitoring or incentive structure makes agents conform best to the interests and objectives of the principal. From this perspective the emergence of S\&T indicators can be explained from the need to improve control and shifting the information asymmetry more in favour of the principal (Note 1).

From a policy perspective the focus on the design of incentive structures is intelligible. But it neglects the actions and strategies of agents to convince principals of the value of their objectives. Such actions and strategies are part of the development of science policy systems and cannot be ignored when analyzing the role of S\&T indicators in science policy. In a sociological explanation of principal-agent relations, principal and agent are complemented with third parties. The principal-agent relation is a result of differentiation of functions or systems, which however remain dependent on each other for resources. New actors enter to mediate the relation in order to keep the functions separated while establishing the connection. The result is a principal-agent configuration in which the dynamics of the relation between principal and agent depend on interactions with the third party.

Braun $^{9}$ has used this model to study the development of funding agencies in several countries. The relation between government and funding agencies is highly affected by the socializing effect of the participation of scientists within the processes of the funding agencies (e.g., peer review, research programming). In a study on disciplinary evaluation committees in the Netherlands Van der Meulen ${ }^{10}$ has conceptualized the configuration between government, evaluation committee and discipline as a triplet of principal-agent relations. The evaluation committee temporarily mediates the ongoing relation between government and the discipline and works as an agent of both the government and the discipline.

Three functions of S\&T indicators can be distinguished if we look at the effect of indicators on the principal-agent relation (Van der Meulen ${ }^{27}$ ). First, S\&T indicators increase the competence of principals to control. S\&T indicators provide structured information about performances, that often can be interpreted by the principal itself. (Note 2). Second, they focus the control to those aspects of the performance of agents that can be indicated by the S\&T indicators. Third, they structure the relation between the principal and the agents. Objectives of the principal and the desired performance of the agents can be formulated more specifically.

If their are several functions, the question is which function will dominate in which context, how certain functions mature in certain contexts and how S\&T indicators can be modelled towards certain functions. A first step towards answers on these question is an analysis of the dynamics of S\&T indicators in policy contexts. Three cases of the use 
of S\&T indicators in the Netherlands are presented below. The use of S\&T indicators is related directly to the dynamics of the relevant principal-agent configuration.

\section{S\&T indicators in Dutch science policy: three cases}

In the Netherlands, the government plays an important role in the development of bibliometric methods and indicators, and their use in science policy. Wouters ${ }^{12}$ has shown that the advancement of the use of S\&T indicators is linked to the objectives of the Dutch government to improve the decision processes in science policy and to develop a science policy in which the functioning of the system was important, rather than that of individual organisations, research groups or scientists. But this is true only when focussing on governmental policies. S\&T indicators in general have been implemented more broadly in Dutch science policy and the government has stimulated this (Van Steen ${ }^{13}$ ). One can distinguish four different activities by which S\&T indicators enter into science policy in the Netherlands:

1. The production of a biannual S\&T Indicators Report. S\&T indicator reports were produced irregularly in the eighties. After a pilot in 1991, produced by the Ministries of Education and Sciences and of Economic Affairs, a new series started in 1994, produced by the Netherlands Observatory of Science and Technology. 14,15

2. Ad hoc bibliometric studies produced for specific evaluation purposes. Although the evaluations are not organised by the government any more, some of the bibliometric studies are still financed by the government as a subsidy to improve evaluations, themselves seen as a necessary condition for the well-functioning research systems. An example is the biology disciplinary evaluation which was accompagnied by a citation analysis. ${ }^{16}$

3. Ad hoc indicator studies for certain policy issues. Most of these studies are financed by the government, but also by others. An influential example is Irvine et al.'s study, Investing in the Future, which was extensively quoted by the government in the Science Budget 1991 (Irvine et al. ${ }^{17}$ ).

4. Background studies to develop new bibliometric methods, especially on mapping new developments and social networks in science and technology and on the development of indicators for socio-economic relevance of research. Examples are the studies of the Leiden Centre for Science and Technology Studies on the development of social and behavioral sciences (Nederhof ${ }^{18}$ ) and on mapping integrated science and technology networks (Korevaar et al. ${ }^{19}$ ).

We will discuss examples of the first three kind activities and assess the use of results of S\&T indicator studies and how this relates to the dynamics of Dutch science 
policy. Results of the fourth kind of activities are in general too explorative to be used directly within policy, although the reports do circulate within policy circuits.

\subsection{National $R \& D$ investments}

Since 1991, the S\&T Indicators reports show the Dutch investments in science have decreased as a percentage of GDP from 1987 onwards. The decline is mainly due to reduction of investments in Dutch $R \& D$ activities by some major multi-national firms, with corporate laboratories in the Netherlands. Government investments also show a slight decrease. The typical curve which visualizes this finding can be found in several advisory reports and has become a symbol for those worrying about the health of the Netherlands research system (Fig. 1).

The first signals of the decrease can be found in the 1991 S\&T Indicator Report (Ministry of Education and Sciences (MES) and Ministry of Economic Affairs (MEA). ${ }^{20}$ But the report gives the investment figures until 1989 , so at that time it seems to be a two years decrease only. The accompanying text mentions the decrease in these two years is largest in the Netherlands (from about $2.3 \%$ to $2.1 \%$ ), but continues 'the Netherlands had still a relatively good position among countries of medium size'. In subsequent years the decrease continues to about $1.8 \%$ in 1993. In the 1994 S\&T Indicator Report ${ }^{14}$ it is concluded that the Netherlands has lost contact with countries like Japan, US and Germany, and has to compete with 'followers' like Norway, Finland, Belgium, and the UK. These figures are undisputed at the government level but, at that time, explicitly put in context. It is stressed that one cannot simply interpret the figures at face value. The Dutch economic infrastructure, of which the service sector is an important pillar, has to be taken into account. The nature of the service sector implies a low level of R\&D investments. Also the low level of defense R\&D would legitimate lower overall R\&D investments (see for example: Refs 21, 22). However, in the Science Budget $1995,{ }^{23}$ restoring the $R \& D$ investments as a percentage of GDP to an acceptable level is formulated as one of the objectives of S\&T policy in the next years. The central message of this Science Budget is that links between public research and the private sectors should be increased. Instead of being a matter to be put in context, the decrease of $R \& D$ investments is now presented as a real risk towards a strong economy. Especially industry has to be stimulated to increase its investments in public research. 


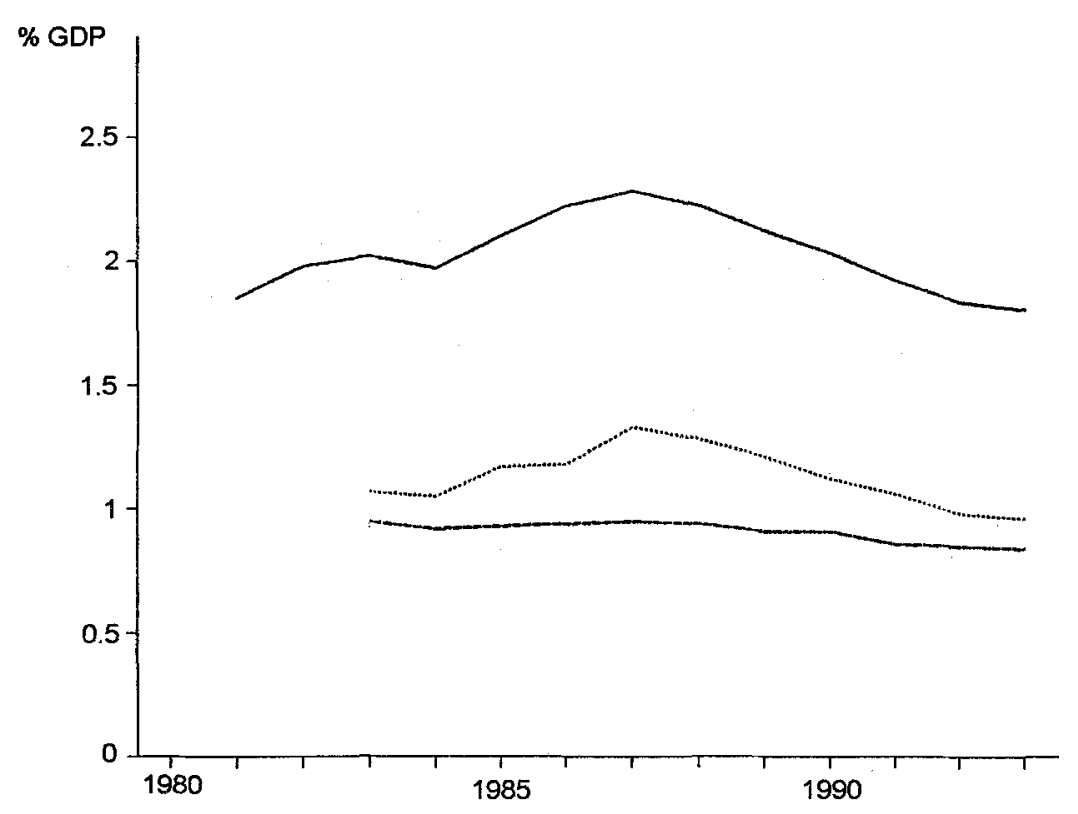

Fig. 1. R\&D expenditures in the Netherlands as \% of GDP (1981-1993) Total expenditures: Government; Industry

For the indicators on national R\&D investments this translation is crucial. At first they were linked within the government-science relation to the governmental spending on research. Now the government has linked them to the industry and its relation with (public) science. From a debatable figure within a long standing principal- agent relation, they have become an established political fact - but in a still maturing relation between industry and public science.

\subsection{Relative allocation of resources}

Of the ad-hoc studies presenting S\&T Indicators, Investing in the Future (Irvine et al. ${ }^{17}$ ) is among the most influential one. The study compares the allocation of resources in six countries, the U.S, the U.K., Germany, France, Japan and the Netherlands. Allocation figures are broken down to funding categories, to categories of research and to fields of research. One of the results is that as percentage of total allocations, the Netherlands spend relatively more on arts and humanities, professional 
studies, social sciences, physical sciences and less on technical sciences, life sciences, environmental sciences and mathematics (Table 1).

Table 1

Allocation of government resources to areas of research, 1987

\begin{tabular}{lrrrrrrr}
\hline & UK & FRG & FRA & NET & US & JAP & Average \\
\hline Engineering sciences & 15.6 & 12.5 & 11.2 & 11.7 & 13.2 & 21.6 & 14.3 \\
Physical sciences & 20.2 & 25.1 & 28.7 & 21.7 & 15.6 & 14.5 & 21.2 \\
Environmental sciences & 6.7 & 4.5 & 5.3 & 2.8 & 5.8 & 3.7 & 4.8 \\
Maths and computing & 7.5 & 3.9 & 5.4 & 3.5 & 4.0 & 2.3 & 4.4 \\
Life sciences & 30.9 & 36.7 & 34.7 & 32.7 & 48.9 & 33.7 & 36.3 \\
Social sciences & 6.7 & 5.2 & 4.6 & 10.4 & 5.1 & 3.9 & 6.0 \\
Professional and vocational & 5.7 & 5.0 & 2.1 & 8.5 & 3.3 & 9.9 & 5.8 \\
Arts and humanities & 6.6 & 6.2 & 6.8 & 8.6 & 2.8 & 9.6 & 6.8 \\
Multidisciplinary & 0.2 & 0.8 & 0.1 & 0.1 & 1.5 & 0.8 & 0.6 \\
\hline Total expenditures (1987 M\$) & 2798 & 4037 & 3212 & 958 & 12904 & 3736 & $100 \%$ \\
\hline
\end{tabular}

Source: Ref. 17, p. 219.

In their final chapter Irvine et al. ${ }^{17}$ warn against hasty interpretations of the findings:

It is necessary to sound a strong note of caution concerning the accuracy of the data reported in this volume. As was apparent in every country chapter, these questions of statistical reliability are central in setting limits on the conclusions that can be legitimately drawn.' (p.207-208)

Of the 21 sets of data used for the six countries that were assessed, only three were labelled good, the others 'reasonable reliable' or 'fair only'. But 'even if data were labelled 'good', they are invariably still subject to a degree of uncertainty.' (Irvine et al. ${ }^{17}$ p. 209 ).

In the Science Budget 1991, the Dutch government extensively cites from the study. ${ }^{24}$ Ten pages are used to present the main findings and interpreting the results of this study. Especially the findings on the relative allocation of resources to research areas are emphasized. The Science Budget 1991 notes that science policy is regularly confronted with the question how much should be relatively spent on physical sciences, engineering sciences and life sciences, on social sciences and behavioural sciences, and on arts and humanities. The formulation is subtle and according to the original in the Science Budget. It suggests the six areas can be reduced to three. The conclusions are subtle as well. The limitations in the data mentioned by Irvine et al. makes the 
government to conclude that better figures and additional analyses are needed. These analyses should be provided in a foresight process. Nevertheless, at the same time the government concludes allocation to the natural, engineering and life sciences should be increased.

But the results have a short life cycle. Although the issue of budget allocations remains vividly, the debate concentrates on how government can force changes in budget allocations within universities. A new system of university funding is implemented, which intends to increase somewhat the discretion of the government over the internal university allocation of research funding. But implementing priorities by direct intervention in the universities turns out to be problematic. In its Science Budget $1993^{21}$ the government mentions eight areas that have to be reinforced by the universities. The universities and university departments cooperate and make plans or show that such reinforcement has been effected already. Disciplinary committees coordinate the plans and guide the implementation process. Due course the government has lost sight on it and can only at an abstract level monitor whether priorities were realised. A shift has been made from priorities to processes.

In addition, a foresight process is initiated to provide more information about the relative importance of different research areas. The foresight process was delegated to an ad-hoc committee. The main tasks of the committee are to initiate foresight processes and to advise the government on the outcomes. After some internal pilot studies the committee concludes that doing foresight studies on selected topics is more fruitful than a holistic foresight process aiming at comparing areas, e.g. physical sciences with social sciences. Within the focused studies possible linkages between socio-economic objectives and scientific possibilities can be explored more in detail (Van der Meulen ${ }^{25}$ ). The final report of the committee mentions priority themes instead of priority fields or disciplines. ${ }^{26}$

The international figures on allocation of research funds found their way easily to science policy and became part of the relationship between government and universities. However the shifts made in this relationship from priorities to processes and from priority disciplines to priority themes, reduced their policy relevance significantly.

\subsection{Disciplinary evaluation committees}

Since about 1992, university research is evaluated in an enrolling five year scheme. Each discipline is evaluated every five year. The evalautions are organised by the Association of Dutch Universities and done by international evaluation committees. A stringent protocol defines the organisation of the evaluation process, the information the 
universities have to provide and the criteria the committee should use. The use of bibliometric indicators is common practice for these committees. Publications data are an obligatory part of the information the universities have to provide about the research programmes. All evaluation committees report these figures, and productivity is used as one of the dimensions to assess performance. In general, there is hardly any dispute on the value of these data and on their interpretation.

This was not the case in the eighties. At that time, such committees were organized by the Ministry of Education and Sciences. Committees were installed ad hoc, in those fields where government or research organisations perceived opportunities or major problems e.g. severe budget reductions. While the government promoted the use of bibliometric indicators by these committees, such methods were far from accepted practice. Discussion was about what indicators should be used, how they should be used, who should use them and how to interpret them. In all comments on the distinctive reports the use of indicators appeared prominently.

Table 2

S\&T indicators used by evaluation committees in the eighties

\begin{tabular}{llllll}
\hline $\begin{array}{l}\text { Evaluation } \\
\text { committee }\end{array}$ & \multicolumn{1}{c}{ Science indicators } & \multicolumn{3}{c}{ Comments } \\
\hline Biochemistry & $\begin{array}{l}\text { Number of citations } \\
\text { fellowships; methodological } \\
\text { contributions) }\end{array}$ & positive & negative & negative & negative \\
Biology & $\begin{array}{l}\text { Number of publications } \\
\text { (know how, infrastructure) }\end{array}$ & negative & negative & positive & negative \\
$\begin{array}{l}\text { Economics } \\
\text { Theology }\end{array}$ & $\begin{array}{l}\text { Number of publications } \\
\text { Number of publications }\end{array}$ & $\begin{array}{l}\text { negative } \\
\text { positive }\end{array}$ & $\begin{array}{l}\text { negative } \\
\text { positive }\end{array}$ & $\begin{array}{l}\text { negative } \\
\text { positive }\end{array}$ & $\begin{array}{l}\text { negative } \\
\text { positive }\end{array}$ \\
\hline
\end{tabular}

Table 2 (Van der Meulen ${ }^{27}$ ) lists the kind of indicators used by four of these evaluation committees in the 1980s. One committee used numbers of citations and some other additional indicators to assess performance. Three others, biology, economics and theology, used numbers of publications. Within the table are also listed the responses of main actors within the Dutch research system on these methods. At the governmental level the then Advisory Council for Science Policy (RAWB) was asked to pay specific attention to the method used by the evaluation committee in its comments. It reacted positively on the use of citations and on the publication counting by the committee for theology. The Netherlands Research Council (ZWO), the Royal Netherlands Academy of Arts and Sciences (KNAW) and the Universities were all negative on the use of citations. With respect to the use of publications they were all 
negative as well in the case of the economy evaluation and all positive in the case of the theology evaluation. Opinions diverged in the case of the biology evaluation. The research council responded positively. Like the advisory council, the Academy and the universities responded negatively.

Within science policy in these days there was no accepted scientometric method and no dominant opinion on these methods. In a study on the use of indicators by these committees Van der Meulen ${ }^{27}$ concluded that the acceptance of the indicators depended on acceptance of the conclusions. A crucial issue in the responses was whether the committee had indeed assessed the main problems the disciplines faced with. Sometimes these problems were on the level of budget reductions and selection of priorities. Other disciplines faced new relations with society or unbalanced developments of subdisciplines. Actors that agreed with the disciplinary evaluation committee about the main problems, responded positively on the indicators used. Those who saw rather different problems stressed the inappropriateness of the indicators used to deal with these problems or rejected them even firmer when the assessment seem to enlarge the problem (e.g., centralistic intervention).

The debate has been closed now on two levels. The practice of using bibliometric methods for assessing research groups and departments has become codified within the protocols. The indicators are used, even when there is no urgency for a bibliometric analysis or when the discipline lacks a codified publication practice to validate the interpretation of the indicators. The debate as a process has also been closed. In the eighties reports were sent to actors for advice and the government responded officially. Presently, reports are sent to the main bodies in the research system just to inform them. Universities are expected to respond by implementing the outcomes. So, instead of being part of a highly conflicting policy relation between government and science, dominated by budget restrictions and doubts about performances, the indicators are now part of the management practices of universities.

\section{Discussion and conclusions}

It is interesting to contrast the two areas of science policy in the Netherlands in the way bibliometrics are used: monitoring and evaluation. From a scientometric point of view, governmental science policy seems to be characterized by opportunistic use, misuse and sometimes abuse of bibliometric data. The evaluation procedures are characterized - from the scientometric point of view - by interpretation of bibliometric indicators by knowledgeable people. But that is a too easy criticism, neglecting the specific rationality, call it 'political rationality', of science policy. 
In order to understand the effects and uses of S\&T indicators they should be related to the socio-political context in which they are used. Therefore I have introduced the notion of principal-agent configurations as a returning configuration in science policy, especially when it concerns S\&T indicators. The analyses of the use of S\&T indicators in science policy can then be broken down into three steps. First, the identification of the principal-agent configuration in which the indicators will be used. The second step is to analyze how bibliometric indicators affect the (socio-political) relations within the configuration. The last step is to add the time dimension, and analyze the dynamics of the principal-agent configuration.

In the case of disciplinary evaluation committees the configuration consists of the relation between government as a principal, the discipline as a community of agents and the evaluation committee as a temporary, mediating third party. The indicators improve the capability of the committee to evaluate. With respect to the main principal-agent relation in the configuration, the relation between government and the discipline, the position of the government is strengthened. The indicators empower the principal to form a legitimate opinion on the performance of the agents and on the validity of the assessments of the disciplinary evaluation committee. At least that was the situation in the 1980s.

The institutionalisation of the evaluation committees by the Association of Dutch Universities differentiates 'evaluation' as a separate function of science policy. The committees now become an agent of both disciplines and government. The result is a complex principal-agent configuration in which the discipline is both agent of the government and a partial principal of the committee. The relation between committee and government is mediated by the Association of Dutch University. (Note 3). The differentiation implies a stabilization of evaluation practices and a possibility for bibliometric methods to become part of the evaluative repertoire. But the differentiation has its costs as well. Because of the differentiation of the evaluation function from science policy, its effects on other functions of science policy are minimized. In contrast with the results of the committees in the 1980s, results of the present evaluation committees are hardly adopted in science policy. Thus, the role of the S\&T indicators for evaluation has grown, but at the same time their impact decreased.

In the two cases on S\&T indicators used in the Science Budgets of the government the main principal-agent relation is the one between the political system and the scientific system or the university system. Science policy as it was developed in the Ministry of Education and Sciences, mediates between these two. Indicators on investments are used to inform the principal about the performance of the agent, and to legitimate the mediation: i.e., science policy. The fate of the bibliometric indicators is 
closely related to the way in which science policy tries to combine and optimize the functions of the political system and the scientific system. The indicators serve to translate objectives and interests from the one system to the other.

In the case of national $R \& D$ investments the indicators first sensitize the political system to the development of the scientific system and the possible problems a decline might have. Acceptability of the indicators is increased by putting them in context. Later on, indicators can speak for themselves and become an accepted fact within the political discussion on S\&T policy. In the second case the indicators on relative budget allocations were used to translate the objective of the political system, i.e. to optimize allocation and increase the economic benefits of science, to objectives for the science system. However, the translation of this objective is done in another way as well: with a new university funding scheme and the introduction of a foresight process. These two changes affect the principal-agent relation. The science system develops means to cope with the objective of the political system to increase selectivity in a way the indicators lose their significance.

It is easy to be-cynical or frustrated about how S\&T indicators are used, misused and abused in science policy. Especially, if one supposes that these indicators are worthwhile and proper use is prevented by the irrationalities of policy makers. However, bibliometric data do not just emerge in a scientific market in which scientists win or lose according to their talents and reputation, nor in a despotic state in which a government rules with crude indicators and arbitrariness. They are part of complex authority configurations in which agents try to mediate between actors who (selectively) fund and promote science and the scientists.

What is the added value if we look upon the use of S\&T indicators in this way? Can we now make better indicators and be more sure about proper use? Not automatically. With hindsight we can make a kind of mechanical analysis, but designers and producers of indicators have to look forwards. Definitely, the third step, adding the dynamic of the configuration to the analysis, introduces a major uncertainty. The configurations depend not only on the S\&T indicators but have other dimensions as well.

However, let me conclude by giving three indications how a context analysis might be useful in the design and production S\&T indicators. The first is that context analysis shows that those who will use the reports are not always the direct clients. In evaluations for instance, the evaluation committee seems to be the primary client. But if the indicators are presented in a separate report, a government, or another research funder will be interested in the outcomes as well. Even if evaluation committees do not use the indicators, the bibliometric study can have its use for the relation between the government and its agents. 
Similarly, the circle of customers can be reduced deliberatedly by adjusting the indicators and their representations to the information need and capacity of one actor only. Science policy at a government level can handle S\&T indicators only at great level of abstraction (e.g. disciplines, sectors or kind of institutions). Within management practices much more detailed analyses are needed, e.g. on the level of programmes, projects or even persons. Analyses of the policy context of indicator use paves the way to tailor made S\&T indicators $\left(\mathrm{Katz}^{28}\right)$.

Definitely, the provision of such data empowers actors with monitoring and control capacities. It is of course an important issue which actors should be empowered and with what capacity. Producers of S\&T indicators can not evade this question and being just responsive to market demands. A critical reflection on what good S\&T policies are and how S\&T indicators should contribute to these is needed. An essential part of such reflection is a good understanding of the configuration in which indicators are used, which indicators can be taken up, and how they can affect strategies of all actors.

\section{Notes}

1. It is significant that groups in the UK and the Netherlands have played a major role in the development of performance indicators at a time when research policy in these countries was characterised by budget restrictions and assessments (Martin and Irvine, ${ }^{7}$ Moed et al. ${ }^{8}$ ).

2. Producers of S\&T indicators tend to overemphasize the necessity of asking peers about the interpretation. First, by structuring the information in a certain way, they give part of the interpretation themselves. Second, a lot of S\&T indicators are build on a level of aggregation that is beyond the usual scope of peers.

3. Note that when complex configurations stabilize over time, actors often do not perceive the basic relations any more. The dependencies and accountability become apparent again only when the main function of the configuration, in this case 'evaluation', is disputed. Recently, the Dutch government dismissed an evaluation of educational programs in physics at universities, because it was too much a defense of the discipline. The affair brought into light again that these evaluations are not just done to serve the university management, but also to show accountability to the government.

\section{References}

1. S. ZELDENRUST, Ambiguity, Choice and Control in Research, PhD thesis, Universiteit van Amsterdam, 1989.

2. B. J. R. VAN DER MEULEN, A. RIP, Research Institutes in Transition, Delft, Eburon, 1994.

3. R. MAYNTZ, F. W. SCHARPF, Chances and problems in the political guidance of research systems, in: H. KRUPP (Ed.), Technikpolitik angesichts der Umweltkatastrophe, Heidelberg, Physica Verlag, 1990, pp. 61-83.

4. R. WESTFALL, Science and patronage: Galileo and the telescope, Isis, 76 (1985) 311-330.

5. S. P. TURNER, Forms of patronage, in: S. E. COZZENS, T. Y. GIERYN (Eds), Theories of Science in Society, Bloomington, Indiana Univ. Press, 1990, pp. 185-211.

6. S. E. COZZENS, P. HEALEY, A. RIP, J. ZIMAN, The Research System in Transition, Dordrecht, Kluwer Academic Publisher, 1990. 
7. B. MARTIN, J. IRVINE, Assessing basic research: some partial indicators of scientific progress in radio astronomy, Research Policy, 12 (1983) 61-90.

8. H. F. MOED, W. J. M. BURGER, J. G. FRANKFORT, A. F. J. VAN RAAN, The use of bibliometric data for the measurement of university research performance, Research Policy, 14 (1985) 131-149.

9. D. BRAUN, Who governs funding agencies, the principal-agent relationship in research policy-making, Journal of Public Policy, 13 (1993) 135-162.

10. B. J. R. VAN DER MEULEN, Evaluation Processes in Science: the Construction of Quality by Science, Government and Industry, $\mathrm{PhD}$ thesis, University of Twente, 1992.

12. P. WOUTERS, Cijfers voor beleid, vragen voor wetenschap; De opkomst van indicatoren in het Nederlandse wetenschapsbeleid, Kennis en Methode, 16 (1992) 128-147.

13. J. VAN STEEN, S\&T Indicators in science policy: how can they matter? Research Evaluation, forthcoming.

14. NEDERLANDS OBSERVATORIUM VAN WETENSCHAP EN TECHNOLOGY (NOWT), Wetenschaps- en Technologie-Indicatoren 1994, Zoetermeer, Ministerie van Onderwijs en Wetenschappen, 1994.

15. NEDERLANDS OBSERVATORIUM VAN WETENSCHAP EN TECHNOLOGY (NOWT), Wetenschaps- en Technologie-Indicatoren 1996, Zoetermeer, Ministerie van Onderwijs en Wetenschappen, 1996.

16. VERENIGING VAN SAMENWERKENDE NEDERLANDSE UNIVERSITEITEN (VSNU), Netherlands Biology in the Nineties (part one and part two), Utrecht, VSNU, 1994.

17. J. IRVINE, B. MARTIN, PH. ISARD, Investing in the Future, an International Comparison of Governmental Funding of Academic and Related Research, Aldershot, Edward Elgar Publishing Company, 1990.

18. T. NEDERHOF, Mapping the Social and Behavioral Sciences: 1991-1994, a port-folio analysis of research in the Netherlands, CWTS, University of Leiden, Leiden, 1996.

19. J. C. KOREVAAR, R. J. W. TIJSSEN, A. F. J. VAN RAAN, Actoren in de wisselwerking tussen wetenschap en technologie: samenwerking en kennisnetwerken in Nederlands katalyse onderzoek, Centre for Science and Technology Studies CWTS, University of Leiden, Leiden, 1994.

20. MINISTERY OF EDUCATION AND SCIENCES, MINISTERY OF ECONOMIC AFFAIRS, TWIN, Technologie en Wetenschapsindicatoren, Ministerie van Onderwijs en Wetenschappen, Zoetermeer, 1992.

21. MINISTERY OF EDUCATION AND SCIENCES, Wetenschapsbudget 1993, Tweede Kamer, Vergaderjaar 1992-1993, 22959,1992:

22. ADVIESRAAD VOOR HET WETENSCHAP EN TECHNOLOGIEBELED, Technologiebeleid en Economische Structuur, Den Haag, April 1994.

23. MINISTERY OF EDUCATION, CULTURE AND SCIENCES, Wetenschapsbudget 1995, Tweede Kamer, Vergaderjaar 1994 1995, 23965, 1994.

24. MINISTERY OF EDUCATION AND SCIENCES, Wetenschapsbudget 1991, Tweede Kamer der StatenGeneraal, Vergaderjaar 1989-1990, 21805, nrs. 1-2, 1990.

25. B. J. R. VAN DER MEULEN, Heterogeneity and co-ordination: The experience of the Dutch Foresight Steering Committee, STI-Review, 17 (1996) 161-175.

26. OVERLEG COMMISSIE VERKENNINGEN (OCV), Een Vitaal Kennissysteem. Nederlands onderzoek in toekomst perspectief, OCV, Amsterdam, 1996.

27. B. J. R. VAN DER MEULEN, Indicators in a framework of judgement and control, In: P. WEINGART, R. SEHRINGER, M. WNTERHAGER (Eds) Representations of Science and Technology; Proceedings of the Internatianal Conference on Science and Technology Indicators, Bielefeld, 10-12 June 1990, Leiden, DSWO Press, 1992, pp. 57--74.

28. J. S. KATZ, Desktop scientometrics, Scientometrics, this issue. 